\title{
A Autopercepção da Proatividade Social Juvenil na Transformaç̃ão Social: uma abordagem baseada em mineração de dados
}

\section{The Self-perception on the Youth Social Proactivity in the Social Transformation: a Data Mining Based Approach}

\begin{abstract}
Resumo:
Este trabalho enfoca como o estudante considera a própria proatividade social em um contexto de transformação social. Parte de um Projeto Educativo Institucional que acredita na centralidade do jovem no processo educativo. O referencial teórico se baseia em três pilares: Lacan (sobre o Real, o Simbólico e o Imaginário), Maturana e Varela (que consideram os seres humanos como organismos autopoiéticos) e Casanova (que analisa criticamente o conceito de habitus bourdieusiano para balizar as orientações sociais em relação à transformação social). No método, apresenta um caso de aplicação de tecnologias de Mineração de Dados para conhecer a autopercepção do estudante em relação ao seu papel social. O método CRISP-DM e o Modelo Neural Combinatório foram usados para obtenção de padrões entre dados de um questionário socioeconômico e redações escritas por ocasião de concurso vestibular. Busca-se subsidiar a tomada de decisão dos educadores e gestores de instituições educativas com informações sobre o perfil de seus estudantes.

Palavras-chave: Proatividade Social. Mudança Social. Mineração de Dados. Modelo Neural Combinatório.
\end{abstract}

\section{Abstract:}

This work is focused on how the students consider the selfproactivity in a context of social transformation. It starts from an Institucional Educational Project, which adopts the Preventive System of Education and believes in the young centrality in the educational process. The theoretical framework is based on three pillars: Lacan (about the Real, the Symbolic and the Imaginary), Maturana and Varela (that consider the human beings as autopoietic organisms) and Casanova (with a critical analysis on the Bourdieusian concept of habitus in order to mark the social orientations toward social changes). In the method, it reports a case of application of Data Mining for understanding the student view on her/his social role. CRISP-DM method and the Combinatorial Neural Model were applied to obtain patterns from a socioeconomic survey and texts written during the selection for entering the undergraduate courses. It aims at subsidizing educators and managers of educational institutions in decision making with information on the students' profile.

Keywords: Social Proactivity. Social Chang. Data Mining. Combinatorial Neural Model.

SANTOS, Geraldo Magela Freitas dos; FERNEDA, Edilson; PRADO, Hércules Antonio do; GONZÁLEZ, Freddy Álvarez. A Autopercepção da Proatividade Social Juvenil na Transformação Social: uma abordagem baseada em mineração de dados. Informática na Educação: teoria \& prática, Porto Alegre, v. 14, n. 2, p. 13-32, jul./dez. 2011.

\author{
Geraldo Magela Freitas dos Santos \\ Centro Universitário do Espírito Santo \\ Edilson Ferneda \\ Universidade Católica de Brasília \\ Hércules Antonio do Prado \\ Universidade Católica de Brasília \\ Freddy Álvarez González \\ Universidad Politécnica Salesiana
}

\section{Introdução}

0 protagonismo juvenil é uma expressão que traduz uma concepção de jovem como sujeito de direitos, com poder de participar democraticamente da transformação social (STAMATO, 2009). O jovem educando é, assim, concebido como sujeito, com capacidade para o exercício do protagonismo, capaz de fazer escolhas e, assim, intervir, de alguma forma, na construção de sua trajetória de vida e contribuir para a melhoria da sociedade.

Trabalhos como os de Mitrulis (2002) e de Andrade e Nunes (2005) apontam o protagonismo juvenil como uma forma de se contrapor à violência e desinteresse dos jovens. Assim, em um processo de educação para valores, faz-se necessário conhecer a disposição social do jovem histórico que se nos apresenta. A 
disposição proativa em relação à participação social é sinalizadora de uma atitude protagonista que contribua para a transformação social, permitindo a construção participativa de um itinerário educativo.

O trabalho aqui apresentado se situa no contexto de uma Instituição de Ensino Superior confessional, que pertence a uma rede de instituições cuja missão é a educação da juventude numa perspectiva humanista. Seu Projeto Educativo Institucional baseia-se no Sistema Preventivo de Educação, nome dado ao sistema pedagógico de D. Bosco, educador da juventude, cujo sistema de educação, segundo Gomes (1991, apud CAMARGO, D. M. P. e ALBUQUERQUE, J. G. p. 448), seria "um corpo que reúne práticas que se tornaram tradição, normas pedagógicas e regulamentos aplicados à gestão das escolas salesianas, desde a metade do século XIX". Entre os princípios desse Sistema Preventivo está o protagonismo juvenil (DICASTÉRIO PARA A PASTORAL JUVENIL, 2004).

Considerando-se o caráter interdisciplinar da temática que envolve a proatividade e a transformação social, realiza-se, na seção 2, uma trajetória teórica em quatro momentos. Busca-se compreender a percepção dos jovens sobre o fenômeno da desigualdade social e sobre os agentes da mudança social, sob a abordagem lacaniana, quando estabelece a distinção e a relação entre o Real, o Simbólico e o Imaginário (LACAN, 2005, 2006), bem como sob a abordagem de Maturana e Varela (2001), quando vê os seres humanos como organismos autopoiéticos, que vivem num acoplamento estrutural, natural, social, cultural e linguístico. Enquanto disposição para a ação, analisa-se a proatividade do agente social em relação ao meio social e em relação a si próprio (CASANOVA, 2007), revelando pessoas dispostas ou não a serem proativas em sua responsabilidade social, proatividade essa que é uma disposição prévia ao protagonismo juvenil como projeto educativo. Faz-se, ao final, a inter-relação entre essas abordagens teóricas.

Diante da necessidade de identificação do perfil dos ingressantes no ensino superior, em geral, e da disposição proativa dos mesmos, especificamente, diante da desigualdade social, este trabalho relata um estudo de caso, pesquisando-se a autopercepção dos vestibulandos em relação à proatividade social, associada ao perfil socioeconômico. Para a obtenção de padrões no grupo pesquisado, a mineração de dados foi a metodologia escolhida. Assim, nas seções 4 e 5 são apresentados, respectivamente a abordagem de mineração de dados adotada e os resultados alcançados em nosso estudo de caso.

\section{A Proatividade na Transformação Social: a percepção da realidade, estruturada e estruturante, e a disposição social para a ação}

\subsection{O Fenômeno da Percepção Humana na Sua Relação com o Real, o Simbólico e o Imaginário, na Abordagem Lacaniana}

O real, o simbólico e o imaginário são uma tripartição para fins didáticos. "São três tipos de registros, três sistemas de referência, três domínios da ação inter-humana, três planos que não se recobrem" (LACAN, 1986, p. 157, 308), planos básicos para a compreensão da experiência do sujeito.

\section{O Real}

Fundamentalmente, o que está em jogo é a questão do sentido, como organizador da realidade: buscar, atribuir e captar sentidos, no mundo da linguagem e da intersubjetividade. 
A questão da existência e do acesso ao real sempre foi problemática na história da humanidade. Quando nascemos, há algo exterior e anterior à nossa existência. O problema começa tão logo haja a primeira tentativa de se fazer qualquer afirmação acerca desse real. "Está totalmente fora de cogitação dizer que o real não existia antes. Mas dele nada surge que seja eficaz no campo do sujeito" (LACAN, 1985, p. 276).

A realidade é a interface do real, enquanto percebido pelo sujeito histórico-político-socioculturalmente situado, pela relação dialética sujeito-objeto e Eu-mundo exterior, podendo até o Eu ser objeto, graças à função imaginária. "Não há apreensão do objeto à revelia do sujeito" (LACAN, 1985, p. 315). "Que uma coisa exista realmente ou não, pouco importa. Ela pode perfeitamente existir no sentido pleno do termo mesmo que não exista realmente" (LACAN, 1985, p. 125, 184, 288).

A tensão exterioridade-interioridade não se dá no real, mas no simbólico. A percepção da realidade remete-se, dialeticamente, ao fenômeno. Falar do fenômeno é falar do olhar, numa relação simbólico-imaginária (LACAN, 1986).

A percepção do mundo exterior, chamado de mundo real, não é senão um acesso a "um mundo humanizado, simbolizado, feita da transcendência introduzida pelo símbolo na realidade primitiva [...]" (LACAN, 1986, p. 105). O ser humano não se reduz a um olho, embora toda abordagem represente um olhar e uma perspectiva sobre a realidade (LACAN, 1986).

\section{O Simbólico}

O símbolo pode ser entendido como uma representação de algo, através de uma codificação convencional, permitindo, assim, a comunicação humana. Introjetamos e projetamos símbolos. Na introjeção, o que introjetamos é a palavra do outro (LACAN, 1986).
O homem, para tornar-se humano, tem de, minimamente, entrar na relação simbólica, intervindo em todos os momentos e níveis de sua existência (LACAN, 1986). O que acontece na vida dos sujeitos humanos "depende da maneira pela qual as questões se introduziram em sua história historizada-historizante" (LACAN, 1985, p. 272).

É no nível simbólico, identificado pela linguagem, que reside a parte essencial da experiência humana, enquanto experiência do sujeito (LACAN, 1985, 1986). O sujeito é o autor da palavra, que se manifesta através de ou apesar do sujeito. A noção de verdadeiro e falso pressupõe a palavra: "[...] não há nem verdadeiro nem falso, antes da palavra " (LACAN, 1985, p. 261, 303).

É pela palavra que nominamos as coisas, tendo a capacidade de evocar a presença e de conservar a presença na ausência, estruturando a percepção humana, com base no pacto simbólico, pela concordância em reconhecer o mesmo objeto (LACAN, 1985).

A linguagem tem como referência o conjunto da situação em que se dá (LACAN, 1986). O diálogo é a realização plena da palavra na intersubjetividade, que se dá em dois planos: o do reconhecimento intersubjetivo e o da comunicação (LACAN, 1986).

Há falas que são fundadoras, envolvendo toda a experiência de vida que constitui o sujeito, e, ao fundar a relação intersubjetiva, os sujeitos dessa relação são modificados retroativamente por ela (LACAN, 1986). Assim, o ser humano não pode escapar à relação simbólica. Raramente nos damos conta de que há um enorme abismo, por exemplo, entre um círculo e o sol que ele venha representar. Daí que o símbolo só faz sentido se ele se organizar num mundo de símbolos (LACAN, 1985, 1986).

A linguagem é concebida como uma rede de sentidos, uma teia sobre o conjunto das coisas, sobre a totalidade do real. Ela inscreve 
o plano simbólico no plano do real (LACAN, 1986). Não temos verdadeiramente acesso à totalidade de coisa nenhuma. A totalidade é dinâmica e comporta tantas dimensões de análise quanto se queira, e quanto nos permita e nos limita o sistema simbólico adotado para acesso a tal totalidade. Toda tentativa de abordagem à totalidade de algo é um recorte filtrado (por exemplo, a percepção) e previamente direcionado pelo sistema simbólico (histórico-cultural).

A fala tem a propriedade de introduzir no mundo algo que pesa tanto quanto o real, na medida em que o outro acredita nela (LACAN, 1985, 1986).

Os limites da palavra são indescritíveis. Uma vez pronunciada, perde-se o controle sobre os seus limites, porque ela cria a ressonância de todos os seus sentidos, podendo colocar em causa a própria palavra, em um mundo de emergência de sentido (LACAN, 1986).

Há uma relação dialética entre desconhecimento (que não é ignorância) e conhecimento (seu referente), num processo dialético entre o não saber e o saber. $O$ excesso de luz também pode obscurecer, ao invés de esclarecer (LACAN, 1986). Baseando-se em Santo Agostinho, acrescenta que, na comunicação humana, "nenhuma troca é possível senão através da identificação recíproca de dois universos completos da linguagem" (LACAN, 1986, p. 284). O mesmo discurso que permite a comunicação é o discurso que pode impedir a comunicação (LACAN, 1985).

Assim, a forma como lidamos com o símbolo é que marca as relações intersubjetivas, e isso desde a origem. É a relação simbólica que define a posição do sujeito no plano imaginário (LACAN, 1986).

\section{O Imaginário}

O registro do imaginário é composto, enri- quecido e diversificado pela dialética do simbólico em relação ao real. (LACAN, 1986). A percepção humana é entendida como um sistema perceptivo em camadas, em cujo extremo está a consciência. Tudo o que o sujeito humano faz tem algum sentido, comunicado através de seus comportamentos e até pela omissão deles, ou através de funções marginais. "Ele [Freud] coloca o sistema percepção-consciência lá onde tem de estar, ou seja, no âmago da recepção do eu no outro, pois toda a referência imaginária do ser humano está centrada na imagem do semelhante" (LACAN, 1985, p. 155).

O imaginário está inscrito na ordem simbólica, pois a percepção (humana) não é só uma recepção sensorial, mas uma ressignificação no simbólico e no imaginário (LACAN, 1985).

Os objetos se apresentam a nós, através dos órgãos dos sentidos, como imagens, seja através da percepção sensorial, seja através de sua representação interna, subjetiva. Mesmo sendo subjetivas, devem ter alguma aderência à realidade. Se as imagens se soltam da realidade, caímos no mundo dos delírios e das alucinações. Assim, os objetos (enquanto objetos do desejo) participam de uma dupla natureza, real e imaginária (LACAN, 1985), sempre através da mediação simbólica.

A ilusão é também uma das faces da função imaginária, a qual remete à relação do sujeito com suas identificações formadoras e à relação do sujeito com o real (LACAN, 1986).

O Eu é, simultaneamente, "função imaginária e símbolo, determinando, até certo ponto, a estruturação do sujeito" (LACAN, 1985, p. 72). Tanto o plano simbólico quanto o imaginário são recursos com funções de organização da realidade. O outro é nossa referência e nosso espeIho (LACAN, 1986).

O imaginário, se por um lado é estruturado na sua instituição, por outro, é estruturante de sentido. A própria noção de real é uma construção (simbólica) imaginária. A imagem 
exerce, portanto, uma função mediadora e relacional. É o lugar do sujeito no mundo simbólico que Ihe permite relacionar o imaginário ao real, constituindo sua percepção do mundo (LACAN, 1986).

\subsection{Os Seres Humanos e sua Relação com o Meio, na Abordagem de Maturana e Varela}

A proatividade na construção do mundo encontra respaldo na obra de Maturana e Varela (2001), considerando os seres humanos como autopoiéticos, em acoplamento estrutural, natural, social, cultural e linguístico.

O mundo não é acabado e pré-dado. Ele se faz e nós nos fazemos na nossa interação com o mundo físico e social. Ao invés de nos percebermos como seres totalmente condicionados, descobrimos que há um espaço de intervenção e construção de uma sociedade melhor.

A vida é um processo de conhecimento, que não se reduz à representação fiel de uma realidade, como se ela fosse independente do conhecedor. O representacionismo privilegia a objetividade e descarta a subjetividade

A mente como espelho leva a uma visão extrativista do conhecimento em relação à natureza. Estendendo-se às pessoas, aquelas que são tomadas como objeto, delas deve-se extrair o que se pode, desde a mera energia mecânica do trabalho até a subordinação de suas mentes e formas de pensamento, sendo depois descartadas (MATURANA; VARELA, 2001).

Compartilhamos com os seres vivos o processo vital, o que nos coloca como seres construídos e construtores. Essa construção incessante e interativa é um convite à participação nesse processo.

No dilema entre determinação e liberdade, usando-se a metáfora do rio, "nem a correnteza nem a geografia das margens determinam isoladamente o curso fluvial" (MATURANA; VARELA, 2001, p. 10). Na metáfora do timoneiro, não são só os timoneiros que guiam as embarcações, mas também o meio ambiente. Guiamos e somos guiados.

As duas vertentes básicas de Maturana e Varela (2001) são: (i) o conhecimento não se limita ao processamento de informações oriundas de um mundo anterior à experiência do observador; (ii) os seres vivos são autônomos, isto é, autoprodutores.

A autoprodução (autopoiésis) não significa independência e isolamento. Ao contrário, autonomia e dependência passam a ser complementares e não opostos, porque vivemos numa rede de interações. A subjetividade não quer ser superior nem representar a negação da objetividade. O que se busca é uma circularidade produtiva num relacionamento transacional envolvendo a autonomia e a interdependência.

Somos alertados contra a tentação da certeza, num mundo de solidez perceptiva, muitas vezes não contestada. A certeza é igualmente fenômeno cultural, que leva à cegueira diante da possibilidade de novas cosmovisões.

A cegueira da cegueira é não vermos que não vemos. De forma consciente ou não, o que se pensa ser uma captação de uma realidade objetiva traz a "marca indelével de nossa própria estrutura", conforme Maturana e Varela (2001, p. 27), porque as mesmas características do agente ambiental perturbador podem gerar estados neuronais diversos em diferentes perceptores.

A experiência está atrelada à nossa estrutura, de tal modo que não se pode separar a história individual das ações biológicas e sociais em relação ao mundo exterior, por um acoplamento estrutural, condição de existência e sobrevivência histórica.

O conhecimento sobre nosso processo de conhecimento se dá pela reflexão. Da mesma 
forma que um olho não pode se enxergar a si mesmo, há uma dificuldade de análise de nossos instrumentos de análise. Não há muito como escapar a essa circularidade senão através da admissão da provisoriedade de nossos conhecimentos e processos de conhecer, afastando a inquestionabilidade dos mesmos. Surgem, então, dois aforismos: todo ato de conhecer faz surgir um mundo; todo fazer é um conhecer e todo conhecer é um fazer. Então entramos no mundo da linguagem, ao mesmo tempo, nosso instrumento cognitivo e nosso problema, pois "tudo o que é dito é dito por alguém", na expressão de Maturana e Varela (2001, p. 32).

A linguagem possibilita, pois, o fenômeno comunicativo numa rede social e cultural de interações, num intercâmbio de significados. Isto se dá no interior dos fenômenos sociais, através de acoplamentos mútuos, numa rede de interações recíprocas, que vão se formando nas chamadas unidades de terceira ordem (acoplamento social e cultural).

Assim, o mundo que percebemos não é $o$ mundo e, sim, um mundo, que construímos juntamente com os outros.

\subsection{Orientações Sociais e Transformação Social}

Contribuindo para a compreensão da disposição proativa do jovem na transformação social, a abordagem das orientações sociais de Casanova (2007) se inscreve dentro do estudo das sociedades contemporâneas, relacionando reflexividade e ação.

Dentro da linha de pesquisa sobre processos de recomposição social e reconfiguração cultural, Casanova (2007) estudou os processos de continuidade e mudança de orientações socioculturais (associados à escolarização de grau superior), a partir da análise crítica do conceito de habitus bourdieusiano, sobre a natureza social do comportamento humano, ultrapassando uma perspectiva puramente objetivista (condições de vida, independentes da ação humana), ou subjetivista (ação humana sem considerar as condições socioculturais de ocorrência dessa ação).

Ali (2008) mostra a analogia do modelo habitus-campo bourdieusiano, tomado do modelo físico do eletromagnetismo, para ilustrar a explicação das práticas sociais de indivíduos e grupos. Para compreender esse modelo, sintetiza os conceitos de campo social, habitus e capital (econômico, cultural, social etc.), segundo Bourdieu:

Campo social é uma rede de relações objetivas entre as posições ocupadas pelos agentes. Ele fornece uma estrutura que descreve as posições dos agentes e o ambiente em que as interações ocorrem. Os campos são distinguidos pelo fato de que cada um tem seu próprio capital que assume diferentes formas de poder. [...] Assim, o habitus dos agentes e o capital possuído dentro do campo definem as possibilidades e estilo de comportamento dos agentes. (BOURDIEU, 2003 apud ALI, 2008, p. 8)

O habitus é um complexo cultural de disposições sociais, construídas por internalização e naturalização ao longo do processo de socialização (CASANOVA, 2007). Segundo Catani (2009, p. 19), o conceito de habitus em Bourdieu funciona como "princípio gerador das respostas que damos à realidade social".

E Lugli (2009), comentando o conceito de habitus, ressalta como Bourdieu questionou claramente o processo de naturalização das relações sociais, já que, quando se conhece o habitus internalizado de determinada cultu$\mathrm{ra}$, a desigualdade deixa de ser uma questão de dons, de vocação, de destino, e passa a ser uma construção social. Assim como se constrói socialmente a desigualdade, ela tem chances de ser desconstruída. Setton (2002) lembra que o habitus é uma matriz cultural 
de predisposições para a ação, mas que não é um destino. E Álvarez González (2007, p.15) adverte: "a realidade é mais forte do que as vontades, está mais além do desejo".

A matriz de disposições dos agentes humanos é socialmente estruturada e estruturante. Não se poderia falar em uma natureza social humana, mas várias naturezas sociais humanas sócio-histórico-culturais.

Essa matriz de disposições sociais é dinâmica e dialética, implicando a capacidade de pensar-se a si mesmo (reflexão). Ao invés da dominância do automatismo da ação, Casanova (2007) prefere a noção de disposições sociais, como alternativa mais ampla e mais aberta em relação a um princípio gerador de ação tendo como centro os atores sociais. Essas disposições são socialmente estruturadas e estruturantes, e não são exteriores às relações sociais.

As orientações sociais são, portanto, naturalizadas, não num sentido de natureza imutável, mas como processo que leva a diferentes naturezas internalizadas socialmente. Da mesma forma, podem passar por um processo de desnaturalização.

Relacionada a essas concepções, está a percepção do caráter proativo e não proativo dos agentes sociais em relação às possibilidades de integração social e à inexorabilidade ou não da desigualdade social.

Nessa discussão, insere-se a questão da proatividade dos agentes sociais: a disposição de potência ou impotência do sujeito (proatividade, não proatividade) quanto à orientação igualitária ou não igualitária das condições sociais de existência.

\subsection{Relação Entre a Autopoiésis, o Real, Simbólico e Imaginário, e Habitus, Enquanto Disposição Social Para a Ação}

O fio condutor selecionado para o marco teórico no presente trabalho é a proatividade na mudança social. Esse sujeito, proativo ou não, é um ente autopoiético. É dotado da capacidade de auto-organização em resposta às perturbações do ambiente físico e sociocultural (reatividade) e, simultaneamente, da capacidade de organização desse mesmo ambiente (proatividade), ou seja, um sujeito estruturado-estruturante.

Essa capacidade é função de sua posição político-econômico-cultural no campo social, em uma rede de interações sociais, vale dizer, no espaço social, que estrutura a distribuição das formas de poder no universo social, segundo Azevedo (2003), em função do volume e dos tipos de capital, especialmente o capital econômico e o cultural.

A autopoiésis é referida sempre na perspectiva de um observador, que, na teoria do real, simbólico e imaginário, é o perceptor. Essa percepção se dá em um campo de forças (poder) que influencia sua percepção e sua prática (ALI, 2008).

O simbólico e o imaginário, na abordagem lacaniana, que não se dão em um vazio social, são organizadores de sentido que os sujeitos atribuem sobre a realidade, para que essa realidade possua algum significado para eles, ou seja, que lhes permita sobreviver (autoorganizarem-se). A autopercepção é possibilitada pela capacidade de reflexividade da autopoiésis.

O habitus bourdieusiano é uma modalidade, não a única, de acoplamento estrutural dos seres vivos humanos, acoplamento este que é social, cultural, político, linguístico, em relação ao ambiente, pela incorporação de estruturas objetivas e de esquemas de ação que orientam a percepção da situação e, consequentemente, a ação resultante dessa percepção.

Enquanto disposição para agir, a teoria do habitus alerta para o processo de naturaliza- 
ção de relações sociais assimétricas, historicamente construídas, pela internalização da cultura, na história individual, enquanto mecanismo de reprodução do meio social, induzindo observações/percepções sobre as relações sociais. Para a mudança social, é necessária a instalação de novo habitus, vale dizer, de nova cultura, num processo dialético.

O fenômeno da complexa plasticidade (característica da autopoiésis) dos seres humanos abre diferentes possibilidades de ação/reação em relação ao meio. Os sujeitos, produtores e produzidos, adotam ações e reações, que se dão numa rede comunicativa, possibilitada pela linguagem.

A linguagem, estruturalmente um meio simbólico, tem papel fundamental na interação social, produzindo um acoplamento estrutural de terceira ordem, que, através dos símbolos, carrega imagens, revelando formas diferentes de observação/percepção da realidade (cultura, interesses, poder, crenças, valores, ilusões, cegueiras).

Há, portanto, várias modalidades de interferência no ambiente para reproduzi-lo ou para modificá-lo. Os indivíduos e grupos possuem diferentes disposições sociais para a ação em relação ao ambiente. Essas diferenças vão desde a percepção/observação do grau de equidade social até a disposição proativa para a transformação social, podendo culminar numa prática mais, ou menos, protagonista.

Assim, três referenciais de partida diferentes, a abordagem lacaniana de aproximação à realidade, o modelo biológico-social de Varella e a naturalização das relações sociais bourdieusiana, convergem na busca de organizadores de sentido, por parte de perceptores histórico, social e culturalmente estruturadosestruturantes da realidade, que abrem possibilidades dialéticas de maior ou menor disposição de ação em direção à transformação dessa realidade.
Para identificar e analisar a autopercepção juvenil em relação à disposição para a proatividade social, faz-se, nas próximas seções, a descrição da metodologia empregada, utilizando-se como recurso metodológico a mineração de dados, seguida da apresentação e discussão dos resultados, bem como das conclusões do presente estudo.

\section{Mineração de Dados Como uma Forma de Identificação e Análise da Autopercepção Juvenil em Relação à Disposição à Proatividade Social}

Como exposto anteriormente, cada indivíduo se situa e é situado em um campo social. Para caracterizar esse campo social, lida-se com muitas variáveis socioeconômicas, culturais, linguísticas entre outras. Em um estudo empírico, a resultante é uma base de dados com grande número de variáveis. Seu processamento restaria limitado, se ficasse restrito a análises apenas uni e bidimensionais, especialmente quando o que se pretende é a busca de padrões ou regularidades porventura existentes em bases de dados.

Tanto no campo acadêmico, como no corporativo, os bancos de dados estão abarrotados de informações condenadas ao arquivamento ou consultadas apenas para informações triviais. Por essa razão, SILVA (2007) argumenta sobre a adoção da mineração de dados na descoberta do conhecimento implícito em bases de dados: "O grande potencial do conhecimento intrínseco nessas montanhas de dados continua ignorado ou inacessível por muitas instituições. Entretanto, dife-rentes aplicações têm atestado a relevância e poder desta tecnologia" (SILVA, 2007, p. 9).

Por essas razões, escolheu-se o recurso à mineração de dados, planejada segundo o 
Modelo CRISP-DM e o Modelo de Rede Neural Combinatório (MNC), para extração de padrões, conforme se explica a seguir.

\subsection{O Modelo CRISP-DM}

Adotado pela maioria das empresas que utilizam a descoberta de conhecimento através da mineração de dados, CRISP-DM (Cross Industry Standard Process for Data Mining), segundo Chapman et al. (2000), é um modelo de referência para projetos de mineração de dados, que consiste na padronização de conceitos e técnicas em mineração de dados, hierarquizando os conjuntos de tarefas em: (i) fase, (ii) tarefa genérica, (iii) tarefa especializada e (iv) instância do processo. São quatro as dimensões de contextos de mineração de dados consideradas.

O domínio de aplicação é a área específica em que ocorre o projeto de extração de dados. No caso específico, a área em que se desenvolveu o projeto de mineração de dados é a modelagem de um questionário socioeconômico, associado aos dados extraídos das redações de vestibular, como subsídio à gestão educativa, como forma de incorporar as novas tecnologias ao processo de personalização do itinerário educativo.

O tipo de problema de mineração de dados, categoria em que se descreve a classe específica de objetivo(s) a serem alcançados pelo projeto de mineração de dados. No caso, do ponto de vista do conteúdo, o problema que se coloca é a proatividade diante da possibilidade de transformação da sociedade, sob a perspectiva da desigualdade social, identificado através do questionário socioeconômico dos vestibulandos e das respectivas redações (textos produzidos no vestibular).

$\mathrm{O}$ aspecto técnico abrange questões específicas em mineração de dados, descrevendo diferentes desafios (técnicos) que geralmente ocorrem durante a mineração de dados. No caso concreto, várias questões técnicas tiveram de ser enfrentadas no projeto, conforme especificadas mais adiante, na descrição das fases do projeto de mineração de dados.

Ferramentas e técnicas constituem a dimensão em que se especificam quais ferramentas e ou técnicas serão aplicadas durante o projeto de mineração de dados. No caso específico, foi escolhido o MNC.

Segundo Chapman et al. (2000), uma visão geral do ciclo de vida de um projeto de mineração de dados, de acordo com o Modelo de Referência CRISP-DM, pode ser ilustrada pela Figura 1, que apresenta as seis fases do modelo e suas principais interações:

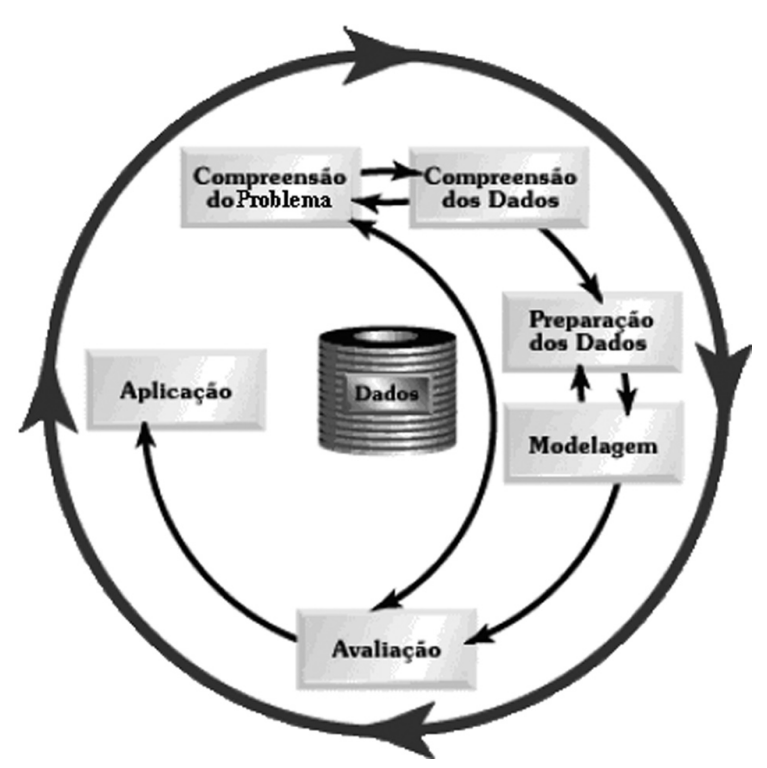

FIGURA 1 - Fases do Modelo de Referência do CRISP-DM FONTE: Adaptado de Chapman et al., 2000, p.13

- Compreensão do problema. Essa primeira fase abrangeu a definição dos objetivos e do problema a ser pesquisado, ou seja, o objeto da mineração de dados. No caso específico, o atributo-alvo foi o protagonismo de jovens e adultos 
vestibulandos em relação à transformação social. Nessa fase, um plano de trabalho e uma metodologia de tratamento da informação foram estabelecidos.

- Compreensão dos dados. Planilhas foram povoadas com os dados dos questionários socioeconômicos e com as categorizações obtidas das redações dos vestibulandos selecionados, sendo realizada uma checagem da qualidade dos dados.

- Preparação dos dados. Os dados foram transformados de acordo com as exigências do MNC e da ferramenta utilizada (Go MINING, versão acadêmica 3.14). Os dois conjuntos de dados foram integrados em uma base única. Foi feita a correção da prevalência de atributos que, segundo Goldschmidt e Passos (2005), influenciariam, de forma distorcida, a mineração de dados.

- Modelagem. Os parâmetros da ferramenta utilizada foram calibrados. Variáveis numéricas foram convertidas em dados categóricos. Várias simulações foram realizadas, com sucessivas transformações dos dados para ajustá-los aos requisitos da mineração de dados e da ferramenta escolhida. Atributos derivados foram gerados, por exemplo, conjugando-se idade com protagonismo para se gerar o atributo alvo.

- Avaliação. Os primeiros resultados foram avaliados e, iterativamente, procedeu-se à criação de novos modelos sobre os dados, confrontando-se os resultados no sentido de maior significância dos resultados. O modelo obtido, na forma de um conjunto de regras, foi ajustado, ou seja, escolheram-se as regras com melhores índices de confiança e suporte, preestabelecidos como indicadores de qualidade.
- Implantação. No caso específico, como se tratava de uma implantação única na pesquisa em foco, o modelo foi implantado e todas as etapas da experiência foram documentadas. Assim, é possível a replicação do estudo em situações análogas. Os relatórios gerados se encontram no texto final da pesquisa e uma parte dos padrões obtidos se encontra sintetizados mais adiante.

\subsection{Redes Neurais Artificiais e Modelo Neural Combinatório}

As Redes Neurais Artificiais (RNA) consistem em modelos matemáticos de processamento que imitam o funcionamento dos neurônios biológicos. Assim, esses modelos conseguem adquirir, armazenar e utilizar um conhecimento experimental. Realizam uma simulação, em termos computacionais, de algumas habilidades humanas como aprendizado, generalização, associação e abstração (GOLDSCHMIDT; PASSOS, 2005).

As redes neurais possuem características semelhantes às do comportamento humano, no que se refere: (i) à busca paralela pela informação, e não uma busca sequencial; em vez de se utilizar um endereço de memória, utiliza-se um endereçamento por conteúdo; (ii) ao aprendizado pela experiência, aprendendo padrões partindo diretamente dos dados, através de algoritmos de aprendizado; (iii) à generalização de conhecimento a partir de exemplos anteriores, eliminando gradativamente os erros ocorridos durante o processo de aprendizagem; (iv) à associação, estabelecendo relações entre padrões de diferentes espécies; ( $v$ ) à abstração, descobrindo características relevantes em um conjunto de dados iniciais; ( $v i)$ à robustez e degradação gradual, não havendo necessariamente um mau funcionamento da Rede, em caso de perda de 
neurônios artificiais; (vii) à diminuição do desempenho da Rede Neural Artificial é gradativa, dependendo da quantidade de neurônios inoperantes.

Há dois tipos de processamento da rede: uma fase de treino e outra de teste. Na fase de treino, dá-se a aprendizagem da rede, que consiste, basicamente, na calibragem de pesos dos neurônios artificiais em função da importância que cada um tem para um resultado esperado ou, pelo menos, para um resultado consistente. Pesos positivos contribuem para a ativação do neurônio seguinte, uma vez atingido o limite previamente estabelecido. Pesos negativos contribuem para a desativação do neurônio receptor. Uma série de processamentos, com variação dos pesos em função dos resultados, procurando minimizar gradativamente a margem de erro, como, por exemplo, através do algoritmo back-propagation (GOLDSCHMIDT; PASSOS, 2005), fazem a RNA aprender. Na fase de teste, dá-se o processamento da recuperação da informação, propriamente dita, com base na "aprendizagem" obtida na fase de treino.

O MNC (MACHADO; ROCHA, 1991) é uma arquitetura computacional híbrida para sistemas inteligentes que integra os paradigmas simbólico e conexionista, sendo uma alternativa adequada para mineração de dados discretos (PRADO et al., 1999). O MNC reconhece regularidades de relações entre os dados, desde que haja redundância entre eles, mapeando dados simbólicos de grande dimensionalidade no espaço de entrada, em relação a saídas de menores dimensões. As características mais interessantes do MNC, segundo Prado, Ferneda e Faria (2010), são: (i) a aprendizagem incremental de novos padrões ao mesmo tempo em que retém padrões já identificados; (ii) a explicitação de padrões entre as variáveis de entrada e as de saída; (iii) a construção de uma rede neural, a partir do conhecimento prévio e (iv) a habilidade para tratar incertezas.

Duas métricas são importantes para a seleção de regras significativas, produzidas pelo MNC: Índice de Confiança (IC) e Suporte (S). O IC de uma regra se refere ao grau de coesão entre as premissas (antecedente - A) e a conclusão (consequente - C) da mesma e indica o percentual de casos ocorridos (antecedente associado ao consequente), em relação ao total do antecedente. Assim,

$$
\mathrm{IC}=(\mathrm{A} \cap \mathrm{C}) / \mathrm{A} * 100
$$

O Suporte (S) indica o percentual de ocorrência da regra, em relação ao consequente (ou classe) da regra. Ou seja,

$$
S=(A \cap C) / C * 100
$$

\section{Um Estudo de Caso}

As razões que deram origem a essa pesquisa foram: (i) o pressuposto de que a dignidade humana é o valor mais alto, não só por seu caráter intrínseco, mas pela necessidade de lutar, como educador, para que esse vaIor, a cada dia, se transforme em realidade histórica; (ii) a crença na proatividade juvenil como uma das forças transformadoras da realidade social; (iii) a necessidade de os gestores de instituições educativas conhecerem os educandos reais, concretos e históricos, que são seus clientes e destinatários, para, mais do que transformá-los em alguma coisa, construírem juntamente com eles um itinerário de formação; (iv) a quantidade significativa de dados existentes nas instituições escolares, carecendo de modelagem a serviço da gestão educativa; $(v)$ a vantagem que representa o domínio de técnicas e ferramentas de inteligência artificial, na descoberta de conhecimento sobre os educandos, por parte 
de educadores e gestores, conhecimento esse que escaparia a uma análise estatística convencional.

O objetivo da pesquisa foi a análise da percepção de um grupo de vestibulandos sobre a própria proatividade na transformação social a partir dos textos produzidos nas redações do vestibular e dos dados do questionário socioeconômico, empregando técnicas de MD. Assim, a questão norteadora foi: Que padrões de associação entre variáveis de um questionário socioeconômico e atributos identificados nas redações, detectados com uso de técnicas de mineração de dados, são de interesse da gestão educativa, na perspectiva da proatividade juvenil na transformação social?

\subsection{Amostragem e Instrumentos}

A pesquisa desenvolvida teve caráter descritivo, enquanto observação, registro, análise e correlação de fenômenos (variáveis) sem manipulá-los. Envolveu pesquisa bibliográfica sobre o conteúdo teórico e metodológico e uma pesquisa documental, na medida em que o ponto de partida foram os textos manuscritos das redações dos vestibulandos. A amostra foi constituída por $20 \%$ do universo de 490 vestibulandos, tomados aleatoriamente, totalizando 98 .

A fonte dos dados foi a Comissão Permanente de Vestibular da Instituição pesquisada. A natureza dos dados abrange dois conjuntos: as respostas ao questionário socioeconômico do vestibular (respostas objetivas) e os textos das redações produzidas pelos vestibulandos, sem a identificação dos autores, posteriormente transformados em dados estruturados através de instrumento próprio de análise.

Em relação ao questionário socioeconômico, foram selecionados os atributos que poderiam representar interesse para a pesquisa, para processamento inicial. Os atributos não geradores de padrões de associação foram eliminados iterativamente. Os atributos numéricos foram convertidos em atributos nominais. A cada atributo foram associados os respectivos domínios.

Os atributos do questionário socioeconômico selecionados, totalizando 31, foram: área, curso, turno, sexo, estado civil, idade, tipo de ensino médio, curso médio, ano de conclusão do ensino médio, pré-vestibular, vestibulares prestados, curso superior, fonte de informação, uso do computador, informação sobre vestibular, motivo de escolha da Faculdade, motivo de escolha do curso, religião, trabaIho do pai, ocupação do pai, escolaridade do pai, trabalho da mãe, ocupação da mãe, escolaridade da mãe, atividade remunerada do candidato, participação econômica na família, renda mensal familiar, pessoas que dependem da renda familiar, compreensão de Inglês, Informática, inscrição em outro vestibular.

Além dos questionários socioeconômicos e das redações selecionadas, foi construído um instrumento de análise das redações, procurando fazer uma cobertura das principais categorias relacionadas à desigualdade social, quanto aos fenômenos, agentes, processos e horizonte da igualdade social, de tal modo que as sentenças das redações pudessem ser classificadas segundo essas categorias. Em cada conjunto, criou-se uma categoria outro, caso as categorias anteriormente previstas no instrumento não fossem suficientes para a classificação das ideias expressas nas redações.

$O$ instrumento de análise das redações foi construído com base em um diagrama conceitual, definindo o tipo de conhecimento a ser descoberto nas redações, conforme explicitado na Figura 2. Cada uma das categorias foi desdobrada em subcategorias (atributos), As subcategorias não expressam afirmações prévias de valor. Foram elaboradas com o intuito de cobrir um possível domínio da categoria 
principal, de modo que todas as sentenças das redações pudessem ser classificadas.

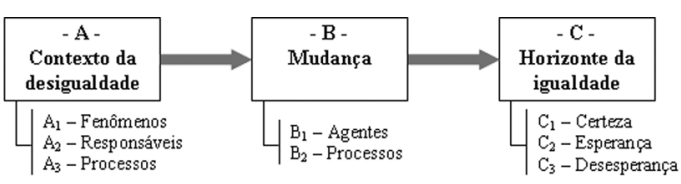

FIGURA 2 - Transformação Social: do contexto da desigualdade ao horizonte da igualdade FONTE: Elaborada pelos autores.

Os fenômenos da desigualdade social incluíram as seguintes possibilidades: desigualdade entre as nações, entre ricos e pobres, de moradia, de etnia, de sexo, de gênero, entre gerações, entre campo-cidade, entre centroperiferia, de qualificação para o trabalho, de escolarização, de cultura, de religião, de classe social, relacionada à infância, à gravidez precoce, a drogas, à violência, a assassinato, outros.

Entre os responsáveis pela desigualdade social, foram incluídas as seguintes possibilidades: eu, nós, juventude, sociedade em geral, sociedade civil organizada, políticos, governo, religiosos, elite, partidos, empresários, ONGs, sistema financeiro, educação, patrões, empregados, natalidade, pobres, bandidos, natureza humana, outros.

Entre os processos ou sistemas que desencadeiam ou alimentam a desigualdade social, foram incluídas as seguintes possibilidades: neoliberalismo, capitalismo, globalização, socialismo, opressão, corrupção, assimetria de poder, preconceito, centrismos, educação, mídia, ideologia, políticas públicas, outros.

Entre os agentes da mudança social, foram incluídas as mesmas alternativas que formavam o conjunto de responsáveis pela desigualdade social.

Entre os processos e dinamismos da mudança social, foram incluídas as seguintes possibilidades: luta, radicalização, história, proatividade, políticas públicas, educação, legislação, ciência, competição, compromisso ético-político, exemplo, valores, religião, ecologia, eleição, outros.

O horizonte da igualdade foi subdivido em três possibilidades: certeza da mudança social, mudanças sociais sob certas condições, desesperança na mudança social.

A variável-alvo ou atributo-classificador, associado a cada redação, foi a proatividade, atributo derivado da conjunção entre idade e os atributos eu ou nós, que, nos textos das redações, eram sujeitos de ações comprometidas com a mudança social. Com base nesse critério, esse atributo teve, como descrição do domínio, quatro possibilidades: (i) jovem proativo, (ii) jovem não proativo, (iii) adulto proativo ou (iv) adulto não proativo. Foi considerado jovem o vestibulando que tinha até 24 anos e, adulto o vestibulando cuja idade era igual ou maior que 25 anos.

As redações da amostra foram analisadas, com base no instrumento anteriormente descrito, por três professores com Mestrado em Letras e experientes na correção de redações, de forma independente. A correlação de Pearson entre as categorizações obtidas pelos três professores que analisaram as redações foi de 0,75 entre o professor $A$ e $B$; de 0,80 entre 0 professor $A$ e $C$; e de 0,85 entre o professor B e o professor C. Portanto, obteve-se uma correlação positiva, acima de moderada e abaixo de forte, segundo Levin (1985). Foram registrados os atributos identificados por pelo menos dois professores. Ao final do processo, $14,3 \%$ dos auto-res das redações foram classificados como jovem proativo, 50,0\% como jovem não proativo, 9,2\% como adulto proativo e $26,5 \%$ como adulto não proativo.

Os dados obtidos foram acrescidos à base de dados do questionário socioeconômico. Para a mineração de dados, foram excluídos os atributos verificados em menos de 10 re- 
dações (pouco significativos para os objetivos do projeto) e aqueles verificados em 96 ou mais redações (sem valor discriminativo numa amostra de 98).

\subsection{Resultados e Discussão}

Preliminarmente, como questão de fundo, cabe ressaltar que a proatividade social é um continuum complexo. Depende de múltiplos fatores e pode ser exercida em diferentes graus. Uma pessoa pode ser proativa em um contexto e não sê-lo em outro. No entanto, nem todas as dimensões mensuráveis o são ao nível de escalas proporcionais ou de razão. Algumas escalas de mensuração só alcançam níveis intervalares, ordinais ou nominais. Escalas nominais expressam apenas as categorias dentro do domínio. Esse é o caso da classificação da proatividade nesse estudo. Não se trata de ignorar o continuum, mas apenas de se obter uma classificação suficiente para as decisões educativas em direção ao desenvolvimento da responsabilidade pela transformação social.

Em média, a quantidade de atributos encontrados, por redação, foi de 7 entre os 96 atributos totais, e de 5,3 entre os atributos potencialmente significativos, ou seja, com o suporte mínimo de $10 \%$. As categorias com suporte inferior a $10 \%$ foram excluídas da base de treinamento. Em relação aos 96 atributos iniciais do instrumento de análise das redações, 19 deles foram potencialmente significativos, representando um aproveitamento de cerca de $20 \%$. A base final de dados para mineração contou com 52 atributos totais, sendo 33 do questionário socioeconômico e 19 do instrumento de análise das redações. As notas obtidas na redação pelos vestibulandos da amostra variaram de 0 a 17 , numa escala de 0 a 20 pontos. A média foi 9,12 e o desvio padrão foi 3,34 .
Foram geradas 1640 regras, com diferentes índices de confiança e de suporte, tendo como atributo-alvo a proatividade, das quais foram selecionadas 71 que atendiam ao IC igual ou maior que $90 \%$ e índice de suporte maior que $10 \%$. A Tabela 1 mostra algumas dessas regras.

Os resultados obtidos com a mineração de dados poderiam ser apresentados de forma mais sistemática, para então serem apresentadas as conclusões, ao invés da apresentação das conclusões com os resultados (selecionados) que Ihes dão suporte. No entanto, devido à grande quantidade de regras, optou-se por fazer uma apresentação das conclusões de forma integrada com os resultados, sobretudo porque os critérios de seleção dos resultados foram as métricas de confiança e suporte, anteriormente mencionados.

O perfil predominante, na amostra pesquisada, é o do jovem não proativo, para o qual a mudança social depende da ação de outros agentes sociais, que não ele próprio. Todos os padrões mencionados a seguir, que descrevem esse jovem não proativo, tiveram um índice de confiança superior a $90 \%$, com suporte variando de $14,29 \%$ a $28,57 \%$.

Conforme as regras obtidas, jovens não proativos podem ser caracterizados de diversas formas alternativas. Para exemplificar, tomemos as duas primeiras regras mostradas na Tabela 1. A primeira regra diz que o jovem não proativo é aquele que prestou apenas um vestibular, seu pai tem trabalho regular e sua nota de redação está entre a média e a média mais um desvio padrão. A segunda regra, de forma alternativa, caracteriza o jovem não proativo como aquele cujo pai estudou até o ensino médio completo, cuja mãe trabalha regularmente e que percebe que a mudança social é de responsabilidade do Governo.

No conjunto completo das 71 regras geradas, constam combinações das seguintes 
TABELA 1 - Exemplo de Modelos Selecionados, a Partir do MNC

\begin{tabular}{|c|c|c|c|c|}
\hline SE & ENTÃO & Confiança & Casos & Suporte \\
\hline $\begin{array}{l}\text { O candidato prestou apenas um vestibular E } \\
\text { O pai tem trabalho regular } E \\
\text { A sua nota de redação } € \text { [média, média + desvio padrão] }\end{array}$ & $\begin{array}{c}\text { Jovem não } \\
\text { proativo }\end{array}$ & $100,00 \%$ & 7 & $14,29 \%$ \\
\hline $\begin{array}{l}\text { A escolaridade do pai é até o ensino médio completo } \mathrm{E} \\
\text { A mãe trabalha regularmente } \mathrm{E} \\
\text { O protagonista da mudança social é o Governo }\end{array}$ & $\begin{array}{c}\text { Jovem não } \\
\text { proativo }\end{array}$ & $100,00 \%$ & 7 & $14,29 \%$ \\
\hline $\begin{array}{l}\text { O candidato não exerce atividade remunerada } \mathrm{E} \\
\text { O seu nível de compreensão de Inglês é regular } \mathrm{E} \\
\text { A sua nota de redação } € \text { [média, média }+ \text { desvio padrão] }\end{array}$ & $\begin{array}{l}\text { Jovem não } \\
\text { proativo }\end{array}$ & $100,00 \%$ & 7 & $14,29 \%$ \\
\hline $\begin{array}{l}\text { Já prestou um vestibular anteriormente } \mathrm{E} \\
\text { Escolheu a Faculdade pela qualidade } \mathrm{E} \\
\text { A mãe trabalha regularmente }\end{array}$ & $\begin{array}{c}\text { Jovem não } \\
\text { proativo }\end{array}$ & $100,00 \%$ & 8 & $16,33 \%$ \\
\hline $\begin{array}{l}\text { Já prestou um vestibular anteriormente } \mathrm{E} \\
\text { O pai trabalha regularmente } \mathrm{E} \\
\text { A escolaridade da mãe é ensino médio }\end{array}$ & $\begin{array}{l}\text { Jovem não } \\
\text { proativo }\end{array}$ & $100,00 \%$ & 8 & $16,33 \%$ \\
\hline $\begin{array}{l}\text { Já prestou um vestibular anteriormente } \mathrm{E} \\
\text { Até cinco pessoas dependem da renda mensal familiar } \mathrm{E} \\
\text { A proatividade da mudança social cabe ao governo }\end{array}$ & $\begin{array}{c}\text { Jovem não } \\
\text { proativo }\end{array}$ & $100,00 \%$ & 8 & $16,33 \%$ \\
\hline $\begin{array}{l}\text { Informou-se sobre o vestibular pela internet } E \\
\text { A mãe trabalha regularmente } E \\
\text { A nota da redação } € \text { [média, média + desvio padrão] }\end{array}$ & $\begin{array}{l}\text { Jovem não } \\
\text { proativo }\end{array}$ & $100,00 \%$ & 8 & $16,33 \%$ \\
\hline $\begin{array}{l}\text { O pai trabalha regularmente } \mathrm{E} \\
\text { Até cinco pessoas dependem da renda mensal familiar } \mathrm{E} \\
\text { A proatividade da mudança social cabe ao governo }\end{array}$ & $\begin{array}{c}\text { Jovem não } \\
\text { proativo }\end{array}$ & $100,00 \%$ & 8 & $16,33 \%$ \\
\hline $\begin{array}{l}\text { A escolaridade do pai é ensino médio } \mathrm{E} \\
\mathrm{A} \text { mãe trabalha regularmente } \mathrm{E} \\
\text { A nota da redação } € \text { [média, média + desvio padrão] }\end{array}$ & $\begin{array}{l}\text { Jovem não } \\
\text { proativo }\end{array}$ & $100,00 \%$ & 8 & $16,33 \%$ \\
\hline $\begin{array}{l}\text { A mãe trabalha regularmente } \mathrm{E} \\
\mathrm{O} \text { candidato está inscrito em outro vestibular } \mathrm{E} \\
\text { A proatividade da mudança social cabe ao governo }\end{array}$ & $\begin{array}{c}\text { Jovem não } \\
\text { proativo }\end{array}$ & $100,00 \%$ & 8 & $16,33 \%$ \\
\hline$\vdots$ & $\vdots$ & $\vdots$ & $\vdots$ & $\vdots$ \\
\hline
\end{tabular}

FONTE: Elaborada pelos autores.

características para jovens não proativos: (i) percepção de que a proatividade pela mudança social é de responsabilidade do Governo; (ii) cursou ensino médio não profissionalizante; (iii) cursou escola particular; (iv) concluiu o ensino médio há menos de três anos; $(v)$ já se submeteu anteriormente a um vestibular; (vi) está inscrito no vestibular de outra instituição; (vii) informou-se sobre o vestibular pela internet; (viii) tem uma compreensão regular de Inglês; (ix) escolheu a faculdade pela sua qualidade; $(x)$ obteve, na redação, nota que se situou entre a média e mais um desvio padrão; ( $x$ i) não exerce atividade remunerada e, consequentemente, não contribui para a renda familiar; (xii) pertence a uma família com até cinco pessoas dependentes da renda familiar; (xiii) o pai trabalha regularmente, (xiv) o pai tem escolaridade de ensino médio; (xv) o pai é empresário; (xvi) a mãe trabalha regularmente; (xvii) a mãe tem escolaridade de ensino médio; ( $x$ viii) tem a desesperança como horizonte da mudança social.

Quando a percepção do horizonte da igualdade social caminha ou não para a esperança ou desesperança, essa percepção está associada à história ontogenética de cada um, pois, na linha de Maturana e Varela, a experiência está atrelada à nossa estrutura, de tal modo que não se pode separar a história individual 
das ações biológicas e sociais em relação ao mundo exterior, por um acoplamento estrutural, condição de existência e sobrevivência histórica. Pela via bourdieusiana, o processo de naturalização das relações sociais, como um arbitrário cultural dominante (NOGUEIRA; NOGUEIRA, 2009), precisa ser problematizado dialogicamente com os jovens, pois, assim como se constrói socialmente a desigualdade, ela tem chances de ser desconstruída.

Prosseguindo, em relação aos padrões encontrados para o adulto não proativo, o MNC o descreve com as seguintes características associadas (IC $=100 \%$ e suporte $=26,92 \%$ ): optou, no vestibular, pela área de humanas; inscreveu-se no Curso de Serviço Social e concluiu o ensino médio há mais de três anos. Com IC $=80 \%$ e suporte $=44,44 \%$, ele é casado, a mãe é aposentada e o pai tem escolaridade apenas até a $4^{a}$ série do ensino fundamental. Com IC $=80 \%$ e suporte $=15,38 \%$, tem o seguinte perfil: cursou um ensino médio profissionalizante; estudou o ensino médio em escola pública estadual; concluiu o ensino médio há mais de três anos; fez um ano de cursinho pré-vestibular; é casado e pertence a uma família com renda mensal familiar de 1 a 3 salários mínimos; tem um pai que é aposentado ou falecido sem deixar pensão; tem uma mãe que tem o ensino fundamental completo, enquanto seu pai tem o ensino fundamental incompleto; segue outra religião (que não as mencionadas no questionário); já se submeteu a dois concursos vestibulares; optou, no vestibular, pelo turno noturno; escoIheu a Faculdade pelo conceito que ela tem no mercado; trabalha, exercendo atividade remunerada com carga horária de 31 a 40 horas semanais, contribuindo para a renda mensal familiar; se estiver já cursando um curso superior, pretende trocar de curso ou abandonar o curso anterior; destaca, como fenômeno de desigualdade social, a diferença entre classes sociais; para diminuir a desigualdade social, aponta como caminhos a educação e as políticas públicas.

Em relação ao vestibulando jovem classificado como proativo, sua mãe é empregada de empresa pequena. Porém o IC desta regra é inferior a $90 \%$ (IC $=75 \%$ e suporte $=$ $21,43 \%$ ). Uma vez que os vestibulandos classificados como não proativos foram a maioria, as regras geradas pelo MNC revelaram padrões apenas para essa categoria.

Considerando que é a situação do sujeito, vale dizer, seu lugar no mundo simbólico, que Ihe permite relacionar o imaginário ao real e igualmente constituir sua percepção do mundo daí resultante (LACAN, 1986), vários fenômenos que manifestam a desigualdade social não foram mencionados nos textos das redações. Isso pode se justificar, em parte, pelo fato de que a capacidade de reflexão sobre a vida social é cultural e socialmente diferenciada, admitindo-se limites a essa capacidade em função das possibilidades oferecidas ou negadas pelas condições sociais.

Dessa forma, não foram destacados pelos textos das redações fenômenos como: desigualdade entre as nações/países, desigualdade habitacional / padrões de moradia / sem teto, orientações sexuais, desigualdade de gênero; desigualdade entre gerações; desigualdade campo-cidade/êxodo rural; desigualdade centro (áreas nobres)-periferia; diferenças religiosas, desamparo da infância; alusão a drogas; alusão à violência / patrimônio / integridade física / insegurança; alusão a assassinatos, alusão à gravidez precoce.

Prevaleceram na descrição dos vestibulandos os fenômenos relacionados à desigualdade entre ricos e pobres, as classes sociais, os preconceitos, com destaque para a discriminação étnica e racial, a desqualificação para o trabalho e desemprego e as diferenças de escolarização ou educacionais. 
Os processos alimentadores da desigualdade social mais destacados foram a assimetria de poder (detentores de poder político e econômico), as políticas públicas, o processo educacional e o sistema capitalista.

$O$ agente social mais destacado foi o governo. Os mecanismos mais destacados, em direção a uma mudança social, foram as políticas públicas, com destaque para a educação e o emprego. Os que acreditam num horizonte de diminuição da desigualdade social, condicionam-no, portanto, às políticas públicas.

Os resultados são uma tradução do imaginário dos vestibulandos, para usar uma categoria lacaniana, que percebem (e têm consciência) do fenômeno da desigualdade social como uma marca negativa de nossa sociedade, com a qual não se pode concordar, se se quer uma sociedade baseada na dignidade humana, como defendido na ética da indignação de Álvarez González (2007).

Quanto a diretrizes de gestão educativa, em relação à autopercepção da proatividade social, o Sistema Preventivo de Educação preconiza a acolhida incondicional ao jovem. Mesmo tendo predominado a categorização de vestibulandos não proativos, o resultado é perfeitamente congruente com essa filosofia de educação, pois não se exigem jovens prontos, segundo a racionalidade dos educadores. Eventuais características consideradas como carências devem ser transformadas em objetivos a atingir e não em pré-requisitos ou exigências para se iniciar um trabalho educativo. A presença educativa, amorosa e solidária é a animadora e ativadora do protagonismo dos próprios jovens, objetivando suscitar neles um renovado empenho para a transformação social do próprio ambiente.

Ainda na gestão educativa, um itinerário formativo poderia ser construído, junto com os vestibulandos ingressantes, com ações da pastoral juvenil universitária, de programas de nivelamento da capacidade de comunicação e expressão escrita em Língua Portuguesa, da Disciplina Religião e Sociedade, de grupos de jovens, nos quais, ao mesmo tempo em que as redações fossem usadas como ponto de partida, fossem discutidos temas relacionados: (i) à diferença entre captar o real e a consciência de ser um perceptor / representador da realidade; (ii) às implicações da linguagem e do imaginário em nossas tentativas de percepção da realidade; (iii) à posição que cada um ocupa no campo social [determinantes políticos (poder) e culturais (formatação cultural pela matriz dominante)]; (iv) às potencialidades e fragilidades na capacidade de ação social; $(v)$ à disposição social para a ação, no contexto de cada um; (vi) a exemplos de boas práticas de ação social; (vi) à proatividade social e ao protagonismo juvenil; (vii) à construção de um programa de ação e mecanismos de interação, avaliação, revisão, ao longo do desenvolvimento do programa.

Quanto a diretrizes de gestão escolar, os padrões obtidos pelo MNC são úteis às estratégias de marketing institucional, com vistas à captação e à retenção de estudantes, e às estratégias pedagógicas, através do uso das informações associadas entre os vários atributos pesquisados como: (i) renda familiar, impactando a determinação dos preços das mensalidades escolares; (ii) conceito que os vestibulandos trazem sobre a instituição e seu posicionamento no mercado; (iii) motivos que levam à escolha de um curso superior, a quantidade de vestibulares a que se submetem, impactando as estratégias de recepção dos calouros e trabalho conjunto do corpo docente do curso, bem como permitindo ações que demonstrem o diferencial da instituição frente às concorrentes; (iv) fornecimento de informações sobre o perfil do ingressante ao corpo docente do curso, permitindo maior personalização das dinâmicas de aprendizagem; 
(v) nível socioeconômico dos ingressantes e políticas de atenção ao estudante; (vi) veículos de comunicação utilizados pelos ingressantes para se informarem sobre a instituição e as decisões sobre propaganda e políticas institucionais de comunicação social; no caso específico, destaque-se o papel dos próprios alunos serem os maiores divulgadores da instituição, o que levaria a um reforço de estratégias de endomarketing, e assim por diante.

\section{Conclusão}

A incorporação da Tecnologia da Informação mostrou-se efetivamente útil como fornecimento de subsídios à gestão educativa. $\mathrm{A}$ aplicação das tecnologias descritas ajudou a traçar dois perfis distintos de vestibulandos: o do jovem não proativo e o do adulto não proativo, considerando-se que a não proatividade foi a característica dominante no grupo pesquisado, conclusão esta que não tem caráter valorativo, tratando-se apenas de atributos classificatórios.

Os modelos gerados efetivamente subsidiam o processo de tomada de decisão nas demais dimensões da gestão escolar, como: gestão administrativa, financeira, publicidade, propaganda, comunicação e marketing, entre outras.

Assim, para melhor personalizar o trabalho educativo, o modelo CRISP-DM mostrou ser um importante recurso na elaboração do projeto de extração de dados e o MNC efetivamente possibilita a descrição do perfil dos jovens que procuram nossas instituições educativas.

Os resultados obtidos na pesquisa refletem as percepções dos jovens, em função de suas condições sociais, históricas, culturais, de forma contextualizada, como ponto de partida para um itinerário educativo, junto com eles, segundo o ritmo que lhe é próprio.

Em relação ao encaminhamento de futuras pesquisas, alguns pontos precisam ser investigados com mais profundidade: (i) a relação entre faixa etária, confissão religiosa, formação para valores humanos, de um lado, e a proatividade na mudança social, de outro lado; (ii) a busca de uma taxonomia para a proatividade social, que ultrapassasse o dualismo classificatório entre proatividade e não proatividade social.

\section{Referências}

ALI, T.M. Self-organization: A New Network Metaphor to Understand the Interdependences of the Organizations and Their Environments. Business Research, Kobe, no. 53, jul., 2008. Disponível em: <http:// www.b.kobe-u.ac.jp/resource/br/pdf/No.53.pdf> Acesso em: 10 out. 2009.

ALVAREZ GONZALEZ, F.J. La ética de la indignación: una ética en tiempos de impotencia. In: CENTRO MUNDIAL DE PENSAMIENTO SUBALTERNO. [site] Quito, 2007. Disponível em: <http://www.cemupesa.org/ index.php?option=com_content\&view $=$ article\&id=72\%3Ala-etica-de-la-indignacion\&catid=35\%3Ainnovacio n-institucional\&Itemid=53\&lang=en> Acesso em: 11 nov. 2009.

ANDRADE, S.F.S.; NUNES, C.A.A. Aprendizagem de Física e Protagonismo Juvenil. In: Simpósio Nacional de Ensino de Física, 16., 2005, Rio de Janeiro. Anais. Rio de Janeiro: CEFET-RJ, 2005. Disponível em: <http:// www.sbf1.sbfisica.org.br/eventos/snef/xvi/cd/resumos/T0592-1.pdf> Acesso em: 12 fev. 2010. 
AZEVEdo, M.L.N. Espaço Social, Campo Social, Habitus e Conceito de Classe Social em Pierre Bourdieu. Revista Espaço Acadêmico, Maringá, ano 3, n. 24, maio 2003. Disponível em: <http://www.espacoacademico. com.br/024/24cneves.htm> Acesso em: 28 ago. 2008.

CAMARgo, D. M. P. e Albuquerque, J. G. O eu e o outro no ensino médio indígena: Alto Rio Negro (AM). Educação e Sociedade, Campinas, vol. 27, n. 95, p. 445-469, maio/ago. 2006. Disponível em: <http://www. scielo.br/pdf/es/v27n95/a07v2795.pdf> Acesso em 29 ago. 2009.

CASANOVA, J.L.S. Orientações Sociais: uma abordagem crítica e operativa ao conceito de habitus. In: CONGRESSO DA ASSOCIAÇÃO PORTUGUESA DE SOCIOLOGIA, 5., 2004, Braga. Actas dos Ateliers. Lisboa: Associação Portuguesa de Sociologia, 2007. Disponível em: <http://www.aps.pt/cms/docs_prv/docs/ DPR4628fe7bb4abb_1.pdf> Acesso em: 17 abr. 2010.

CATANI, D.B. A Educação Como Ela É. Revista Educação, São Paulo, v. 5, p. 19, 2009.

CHAPMAN, P. et al. CRISP-DM 1.0 Step-by-step data mining guide. SPSS. 2000. Disponível em: <http://www. crisp-dm.org/CRISPWP-0800.pdf> Acesso em: 25 ago. 2009.

DICASTÉRIO PARA A PASTORAL JUVENIL. Pastoral Juvenil Salesiana: quadro de referência fundamental. 2. ed. São Paulo: Ed. Salesiana, 2004.

GOLDSCHMIDT, R.; PASSOS, E. Data mining: um guia prático. Rio de Janeiro: Elsevier, 2005.

LACAN, J. O Eu na Teoria de Freud e na Técnica da Psicanálise. 2. ed. Rio de Janeiro, Jorge Zahar Ed., 1985. (O Seminário, 2)

LACAN, J. Os Escritos Técnicos de Freud. Rio de Janeiro: Jorge Zahar Ed., 1986. (O Seminário, 1)

LEVIN, J. Estatística Aplicada a Ciências Humanas. 2. ed. São Paulo: Harbra, 1985.

LUGLI, R.S.G. A Construção Social do Indivíduo. Revista Educação, São Paulo, n. 5, p. 26-35, set. 2007.

MACHADO, R.J.; ROCHA, A.F. The combinatorial neural network: a connectionist model for knowledge based systems. In: BOUCHON, B.; YAGER, R. R.; ZADEH, L. A. Uncertainty in Knowledge Bases. Berlin: SpringerVerlag, 1991. P. 578-587.

MATURANA, H.R.; VARELA, F.J. A Árvore do Conhecimento: as bases biológicas da compreensão humana. São Paulo, Palas Athena, 2001.

MITRULIS, E. Ensaios de Inovação no Ensino Médio. Cadenos de Pesquisa, São Paulo, n. 116, p. 217-244, jul. 2002. Disponível em: <http://www.scielo.br/pdf/cp/n116/14404.pdf> Acesso em: 7 maio 2010. 
NogueIRA, M.A.; NOGUeIRA, C.M.M. Um Arbitrário Cultural Dominante. Revista Educação, São Paulo, n. 5, p. 36-45, set. 2007.

PRADO, H.A. et al. Accuracy Tuning on Combinatorial Neural Model. Lecture Notes in Computer Science, Berlin, v. 1574, p. 247-252, 1999.

PRADO, H.A.; FERNEDA, E.; FARIA, R.C. A Reasoning-based Multi-Goal Strategy For Exploring The Synergy Among Alternative Crops. Lecture Notes in Computer Science, Berlin, v. 6278, p. 174-181, 2010.

SILVA, M.P.S. Mineração de Dados: conceitos, aplicações e experimentos com Weka. [S.I.: s.n.], 2007. Disponível em:

<http://www.lbd.dcc.ufmg.br/colecoes/erirjes/2004/004.pdf> Acesso em: 5 maio 2009.

STAMATO, M.I.C. Protagonismo Juvenil: uma práxis sócio-histórica de formação para a cidadania. In: ENCONTRO NACIONAL DA ASSOCIAÇÃO BRASILEIRA DE PSICOLOGIA SOCIAL (ENABRAPSO), 15., 2009, Maceió. Anais. [S.I.]: ABRAPSO, 2009. Disponível em: <http://abrapso.org.br/siteprincipal/images/Anais_ XVENABRAPSO/389.\%20protagonismo\%20juvenil.pdf> Acesso em: 14 abr. 2010.

Recebido em 20 de junho de 2010.

Aprovado para publicação em 26 de agosto de 2010.

\section{Geraldo Magela Freitas dos Santos}

Centro Universitário do Espírito Santo - UNESC. Colatina/ES - Brasil. E-mail: gemagela@terra.com.br

\section{Edilson Ferneda}

Mestrado em Gestão do Conhecimento e da Tecnologia da Informação. Universidade Católica de Brasília - Brasília/DF - Brasil E-mail: eferneda@pos.ucb.br

\section{Hércules Antonio do Prado}

Mestrado em Gestão do Conhecimento e da Tecnologia da Informação. Universidade Católica de Brasília - Brasília/DF - Brasil. E-mail: \{hercules,renatov\}@ucb.br. e membro da Embrapa - Brazilian Agricultural Research Corporation, E-mail: hercules@embrapa.br

\section{Freddy Álvarez González}

Universidad Politécnica Salesiana. Quito - Equador. E-mail: alvarez.freddy@gmail.com 